\title{
The Effect of Evidence-Based Management Practices on Improving Job Performance: A Structural Equation Modeling
}

\author{
Dr. Hasan Salih Suliman Al-Qudah \\ Health and Hospital Service Management Department, College Of Business, King Abdull Aziz University
}

\begin{abstract}
This study aimed to investigate the effect of Evidence-Based Management Practices on Job Performance at Private Hospitals in Jeddah . a random stratified sample individuals from the employees of the Private Hospitals at Jeddah at three managerial levels totaling (255) individuals. The study applied using SPSS and Amos to do the analysis. The study using a questionnaire to achieve the study objectives through Structural Equation Modeling (SEM). The study results revealed that the Evidence based Knowledge has a significant positive effect on Task Performance and Contextual Performance. This means that the increased one unit in Evidence based Knowledge can significantly increased the same degree in Task Performance and Contextual Performance. As well as, Evidencebased Behaviors has a significant positive effect on Task Performance and Contextual Performance. Finally, Evidence-based Uses has a significant positive effect on Task Performance. Finally, Evidence-based practice trends not a significant effect on Task Performance and Contextual Performance. In addition, Evidence-based Uses has not a significant effect on Contextual Performance.

The study concluded that there exists a statistically significant relationship between some of Evidence-Based Management Practices on Task Performance and Contextual Performance at Private Hospitals in Jeddah . The study found out that there was big contribution of the Evidence-Based Management Practices and job Performance to the Private Hospitals in Jeddah.
\end{abstract}

Keywords: Evidence-Based Management Practices; Job Performance; Private Hospitals and Jeddah.

DOI: $10.7176 / \mathrm{EJBM} / 11-11-03$

Publication date: April $30^{\text {th }} 2019$

\section{Introduction}

Job performance is a vital issue in the lives of individuals and organizations, because the Job performance of each employee is measured by quantitative methods that reflect the diligence, perseverance and skill of each employee, as well as, the seriousness of the employee to acquire experiences through courses and benefit from them. Recent trends in management, especially behavioral ones, have focused on the need to pay attention to the human element, which has led many researchers and academics to pay attention to the subject of Job performance. Job performance is not an objective in itself; it is a means to achieve the objective. This objective is limited to raising the efficiency of the employees, thus benefiting the organization in achieving its objectives and allowing these employees to excel and benefit from promotion opportunities and increase wages.

Accordingly, Rice, et al., (2010) the evidence-based management scales consist of (23) paragraph and three dimensions.

As well as, evidence-based management enhances the quality of management decisions. As well as, Evidence-based management encourages long-term management decisions (Zadeh, 2015).

The basic assumption of this research is the Evidence-Based Management Practices and Job Performance can help Private Hospitals in Jeddah achieve their objectives. More specifically, Evidence-Based Management Practices will affect positively on Job Performance.

In line with the above, the limited Arab studies in the field of Evidence-Based Management Practices and the Job performance, as well as, the limited adoption of these topics in Jordanian organizations, specially, Private Hospitals.

Based on above the current research aims to identify the effect of Evidence-Based Management Practices on Improving Job Performance using a structural equation modeling at Private Hospitals in Jeddah .

\section{Significant of the study}

The significant of the study stems from its quest to emerge results receive more light on the reality of study variables, allows Private Hospitals in Jeddah to view them. In addition to put the recommendations which can be attributed to the decision makers in Private Hospitals in Jeddah to improve the levels of job performance in serve the vision and objectives of Private Hospitals in Jeddah.

\section{Objectives of the study}

Investigate the effect of Evidence-Based Management Practices (Evidence-based practice trends, Evidence-based practices Knowledge, Evidence-based practices Behaviors and Evidence-based practices Uses) on Job Performance (Task Performance and Contextual Performance) at Private Hospitals in Jeddah. 


\section{Research questions}

Based on the research problem statement, its main question and the objectives to be achieve, the following research question need to be answers:

Does the different dimension of Evidence-Based Management Practices (Evidence-based practice trends, Evidence-based practices Knowledge, Evidence-based practices Behaviors and Evidence-based practices Uses) have any effect on Job Performance (Task Performance and Contextual Performance) at Private Hospitals in Jeddah?

\section{Literature Revie}

\subsection{Evidence-Based Management Practices}

The concept of evidence-based practice began to emerge in medicine, specifically in the mid-1990s where doctors found themselves faced the lack of expertise, use of new knowledge and empirical research in practice and adoption of traditional methods of diagnosing patient cases, (Arndt \& Bigelow, 2009)

Evidence-based medicine as an integration of individual clinical experiences with the best clinical evidence available from structured research (Kovner, et al., 2005).

Evidence-based medicine has also been defined as the understandable, honest, clear and judicious use of the best current evidence in patient care decision-making. It means applying the most up-to-date information to address patients' problems, diagnosis, and future vision of disease development, errors and harm and patient safety (Lemieux-Charles \& Champagne, 2004.

Parahoo (2006) points out that evidence-based management is an exercise based on the results of rigorous and reliable research, studies, judgment, practitioners' experience and customer opinions.

Aveyard \& Sharp (2006) also explained that evidence-based management is a practical approach supported by a clear logic, including beneficiary preferences and customers, and the use of authoritative judgments.

Davies (2012) asserts that evidence-based management is a systematic approach to research and assessment of the best evidence and that evidence is used for decision-making, as evidence provided by research takes into account the individual needs of beneficiaries and the results of evidence based on applied research and studies.

According to Tod, et al., (2004) the importance of the evidence-based management approach lies in helping stakeholders by facilitating decision-making, keeping track of technological developments, and giving them the ability and efficiency to achieve goals.

Brown (2013) cited the importance of the evidence-based management approach by providing practitioners with evidence that helps them to research and knowledge and thus provide advice and advice to others and practitioners in the same field.

\subsection{Job Performance}

Vanden Berghe (2011) sees job performance as the multitude of employee behaviors that they display while working. Kaburia (2013) advises that performance "is not ... straightforward ...". Moreover, performance is seen to "consist of complicated series of interacting variables about aspects of the job, the employee and the environment" (Vanden Berghe, 2011).

Armstrong, (2010) opines that individual performance is the result of "ability multiplied by motivation". Thus, an employee's performance is a function (result) of both ability and motivation, for which he provides the formula: Performance $=(f)$ Ability $\times$ Motivation.

The above definitions refer to outputs or outcomes (in terms of accomplishment), as well as stating that performance is about doing the work, as well as being about the results achieved. Performance, which can only occur when employees are motivated and satisfied with their job, is the execution of job-related tasks by employees during the performance of their job, with the doing of such tasks being aimed at ensuring organizational performance as a whole.

Mohammed and Abdul Karim (2015) show that job Performance occupies a special position within an organization as the ultimate outcome of all activities, because the organization is more stable and longer lasting when staff perform distinctly. Thus, the management and leadership of the organization at the level of performance usually exceed the interest of staff.

The importance of the job Performance of the organization is due to its relevance to its life cycle in its various stages, the growth and entry into a more advanced stage depends on their performance levels (Al Murat et al., 2013).

Job performance consists of many parts that are made up of indicators that can differ among various jobs that can be assessed. In the current study the researcher adopts Job performance based on Greenslade \& Jimmieson (2007); Jankingthong \& Rurkkhum (2012); Bursal1, et al., (2014) and Díaz-Vilela, et al., (2015).

The task performance reflects the behaviours that contribute directly to the organization technical core and include those activities that are typically recognized as part of a workers job.

The contextual performance represent the activities that contribute to the effectiveness of the organization 
through many ways that shape the psychological and social context of the organization, which are considered as catalysts for the operations and activities of the mission (Organ, et al., 2006). As well as, the contextual performance are a set of individual efforts that are not directly related to formal organizational functions because they constitute the psychological, social and organizational context that acts as an important catalyst for activities and operations related to tasks at organization (Bursal, et al., 2014).

\subsection{Relationship between Evidence-Based Management Practices and Job Performance}

Bursal1, Bağc and Kök (2014) showed that there is a negative and important relationship between the task performance and surface acting; there is a positive and important relationship between the innovative job performance and deep acting; there is a positive and significant relationship between the natural feelings and task performance, contextual performance and innovative job performance.

Zadeh (2015) concluded that evidence-based management enhances the quality of management decisions. As well as, Evidence-based management encourages long-term management decisions

Rostami, et al., (2015) find out the significant relationship between employees' empowerment and job performance. As well as, there is a significant relationship between consultation and participation of employees with job performance.

\subsection{RESEARCH MODEL AND HYPOTHESES}

Our research model is shown in Fig. 1. The definitions of various constructs in the model. In this study, the authors construct the research model based on reviewing the selected literature on Evidence-Based Management Practices and Job Performance.

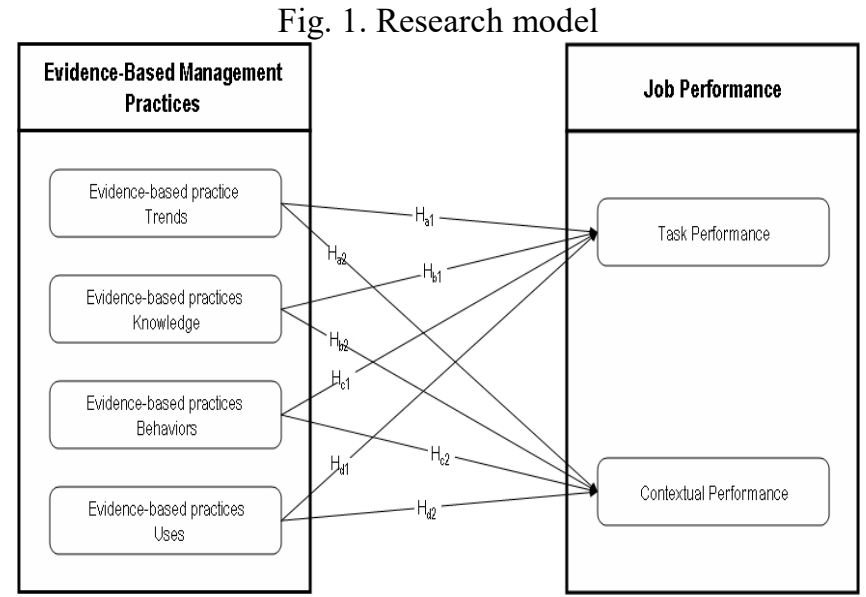

Based on the above discussions, the researcher proposes the following hypothesis:

Ha1. The Evidence-based practice trends positively affects on Task Performance.

Ha2. The Evidence-based practice trends positively affects on Contextual Performance.

$\mathrm{Hb}$. The Evidence-based practices Knowledge Positively affects on Task Performance.

$\mathrm{Hb}$. The Evidence-based practices Knowledge Positively affects on Contextual Performance.

Hc1. The Evidence-based practices Behaviors Positively affects on Task Performance.

Hc2. The Evidence-based practices Behaviors Positively affects on Contextual Performance.

Hd1. The Evidence-based practices Uses Positively affects on Task Performance.

Hd2. The Evidence-based practices Uses Positively affects on Contextual Performance.

\section{Methodology}

6.1. Population and sample

The study population included all employees at three managerial levels in Private Hospitals at Jeddah totaling (1200) individuals.

\subsection{Study Sample}

The sample of the study included a random stratified sample individuals from the employees of the Private Hospitals at Jeddah at three managerial levels totaling (255) individuals.

\subsection{Data collection and instrument}

The data was obtained through a survey. This consisted of the questions in the questionnaire that was sent the responded. Using questionnaire of Evidence-Based Management Practices which was developed by Upton \& 
Upton (2006); Rice, et. al., (2010) and Shi, et. al., (2014). As well as, to measure the Job Performance were adapted Greenslade \& Jimmieson (2007); Jankingthong \& Rurkkhum (2012) and Bursal1, et al., (2014). A questionnaire was prepared to gain answers to specific questions. The items of questionnaire were mainly closed. Likert-type scale was used ranging from $1=$ strongly disagree to 5-strongly agree.

\section{7-DATA ANALYSIS}

The study applied Statistical Package for social science (SPSS) to describe the personal and occupational characteristics of the study sample, as well as, to measuring reliability of the Evidence-Based Management Practices and Job Performance constructs. Structural Equation Modeling (SEM) in data analysis through using the Amos version 23 to test the study hypotheses was used.

\section{Personal, Occupational Characteristics Description}

From table 1 . The researcher observes that the most of the respondents represented mainly by male constituted $60 \%$. Most of the respondents having a bachelor above. However, $83 \%$ of the respondents have experience less than 21 years.

TABLE 1. Personal and Occupational Characteristics

\begin{tabular}{|c|c|c|c|}
\hline Variable & Categorization & Frequency & Percent \\
\hline \multirow{2}{*}{ Gender } & Male & 153 & $60 \%$ \\
\hline & Female & 102 & $40 \%$ \\
\hline \multirow{5}{*}{ Years of Experience } & 5 Years and less & 21 & $8.23 \%$ \\
\hline & From $6-10$ Years & 34 & $13.33 \%$ \\
\hline & From $11-15$ Years & 139 & $54.51 \%$ \\
\hline & From $16-20$ Years & 44 & $17.26 \%$ \\
\hline & 21 and above & 17 & $6.67 \%$ \\
\hline \multirow{3}{*}{ Qualification } & Bachelor & 141 & $55.29 \%$ \\
\hline & Master & 97 & $38.04 \%$ \\
\hline & Doctorate & 17 & $6.67 \%$ \\
\hline
\end{tabular}

\section{Measuring Reliability}

Reliability test was performed one more time to verify whether the Evidence-Based Management Practices and Job Performance constructs are reliable. Reliability results as shown in table 1 clarify that all constructs were higher than the acceptable level stated by Hair. et al., (2006) stated.

Table 2. Reliability Analysis Results for Measurements items

\begin{tabular}{|c|c|c|}
\hline \multirow{2}{*}{ Construct (or factor) } & \multicolumn{2}{|c|}{ Cronbach's alpha } \\
\hline & No of items & Value \\
\hline Evidence-based practice trends & 5 & 0.725 \\
\hline Evidence-based practices Knowledge & 5 & 0.806 \\
\hline Evidence-based practices Behaviors & 5 & 0.807 \\
\hline Evidence-based practices Uses & 5 & 0.741 \\
\hline Evidence-Based Management Practices & 20 & 0.873 \\
\hline Task Performance & 5 & 0.746 \\
\hline Contextual Performance & 5 & 0.778 \\
\hline Job Performance & 10 & 0.818 \\
\hline
\end{tabular}

\section{The hypotheses testing}

The examination the hypotheses using structural equation modeling through AMOS 23.0.

However, the model provided a good fit indicators as: $\chi 2 / \mathrm{df}=2.318$, with the goodness of fit index (GFI) and adjusted goodness of fit index (AGFI) was 0.937 and 0.924 , the normed fit index (NFI) was 0.967, the TuckerLewis coefficient (TLI) was 0.986 , as well as, the comparative fit index (CFI) was 0.984 and the root mean square error of approximation (RMSEA) was 0.051, indicating a good fit between the theoretical model and the data. Table 4 presents each parameter's C.R., Estimate and S.E.

Hence, Evidence-based practice trends has not a significant effect on Task Performance and Contextual Performance $(\beta=0.071$ and $0.033 ; C . R=1.651$ and $-0.635 ;$-value $=0.0 .095$ and 0.511$)$ or Ha1 and Ha2 is not supported.

Evidence based Knowledge has a significant positive effect on Task Performance and Contextual Performance $(\beta=0.779$ and $0.615 ; \mathrm{C} . \mathrm{R}=28.851$ and 21.964; $\mathrm{P}$-value $=* * *$ and $* * *$ or $\mathrm{Hb} 1$ and $\mathrm{Hb} 2$ is supported. Evidence-based Behaviors has a significant positive effect on Task Performance and Contextual Performance ( $\beta$ 
$=0.673$ and $0.423 ; \mathrm{C} . \mathrm{R}=25.884$ and 14.586; P-value $=* * *$ and $* * *)$ or Hc1 and Hc2 is supported.

Table 3. Hypotheses Testing Result

\begin{tabular}{|c|c|c|c|c|c|c|c|}
\hline \multirow{2}{*}{ Hypothesis } & \multicolumn{2}{|l|}{ Regression Weights } & \multirow{2}{*}{ Estimate } & \multirow{2}{*}{ SE } & \multirow{2}{*}{ C.R. } & \multirow{2}{*}{$\begin{array}{l}\mathbf{P} \\
\text { Value }\end{array}$} & \multirow{2}{*}{ Results } \\
\hline & From & To & & & & & \\
\hline Ha1 & $\begin{array}{l}\text { Evidence based } \\
\text { trends }\end{array}$ & Task Performance & 0.071 & 0.430 & 1.651 & 0.095 & Rejected \\
\hline Ha2 & $\begin{array}{l}\text { Evidence based } \\
\text { trends }\end{array}$ & $\begin{array}{l}\text { Contextual } \\
\text { Performance }\end{array}$ & $0.033-$ & 0.520 & -0.635 & 0.511 & Rejected \\
\hline Hb1 & $\begin{array}{ll}\text { Evidence } & \text { based } \\
\text { Knowledge } & \end{array}$ & Task Performance & 0.779 & 0.027 & 28.851 & $* * *$ & Accepted \\
\hline Hb2 & $\begin{array}{l}\text { Evidence-based } \\
\text { Knowledge }\end{array}$ & $\begin{array}{l}\text { Contextual } \\
\text { Performance }\end{array}$ & 0.615 & 0.028 & 21.964 & $* * *$ & Accepted \\
\hline He1 & $\begin{array}{l}\text { Evidence-based } \\
\text { Behaviors }\end{array}$ & Task Performance & 0.673 & 0.026 & 25.884 & $* * *$ & Accepted \\
\hline Hc2 & $\begin{array}{l}\text { Evidence-based } \\
\text { Behaviors }\end{array}$ & $\begin{array}{l}\text { Contextual } \\
\text { Performance }\end{array}$ & 0.423 & 0.029 & 14.586 & $* * *$ & Accepted \\
\hline Hd1 & Evidence-based Uses & Task Performance & 0.339 & 0.041 & 8.268 & $* * *$ & Accepted \\
\hline Hd2 & Evidence-based Uses & $\begin{array}{l}\text { Contextual } \\
\text { Performance }\end{array}$ & 0.065 & 0.750 & 0.867 & 0.187 & Rejected \\
\hline
\end{tabular}

Finally, Evidence-based Uses has a significant positive effect on Task Performance $(\beta=0.339$; C.R $=8.268$; Pvalue $=* * *)$ or Hd1 is supported. as well as, Evidence-based Uses has not a significant effect on Contextual Performance $(\beta=-0.065 ;$ C.R $=0.867$; P-value $=0.187)$ or $\mathrm{Hd} 2$ is not supported.

\section{DISCUSSION}

From analysis, it was observed that the Evidence based Knowledge has a significant positive effect on Task Performance and Contextual Performance. This means that the increased one unit in Evidence based Knowledge can significantly increased the same degree in Task Performance and Contextual Performance. As well as, Evidence-based Behaviors has a significant positive effect on Task Performance and Contextual Performance. Finally, Evidence-based Uses has a significant positive effect on Task Performance. These results consisted with the Zadeh (2015) that concluded evidence-based management enhances the quality of management decisions. As well as, Evidence-based management encourages long-term management decisions.

Evidence-based practice trends not a significant effect on Task Performance and Contextual Performance. In addition, Evidence-based Uses has not a significant effect on Contextual Performance.

\section{CONCLUSION}

From the analysis, it can be concluded that there exists a statistically significant relationship between some of Evidence-Based Management Practices on Task Performance and Contextual Performance at Private Hospitals in Jeddah. The study found out that there was big contribution of the Evidence-Based Management Practices and job Performance to the Private Hospitals in Jeddah .

12.1. Limitation

The study was limited to the Private Hospitals in Jeddah. The study was also limited to top and middle management in the Private Hospitals in Jeddah and not the other organizations in other sector.

12.2. Further research

The studies recommend the extension of this research to examining the Evidence-Based Management Practices on creative performance behaviors.

\section{References}

Al-Murat, A; Anafarta, N \& Sarvanc, F. (2013). The relationship between innovation and firm performance: An empirical evidence from Turkish automotive supplier industry. Procedia - Social and Behavioral Sciences, $75,226-235$.

Armstrong, M. (2010). Essential human resource management practice: A guide to people management. London: Kogan Page.

Arndt, M \& Bigelow, B. (2009). Evidence-Based Management in Health Care Organizations: A Cautionary Note. Health Care Management Review, 34: 206-213.

Aveyard, H \& Sharp, P. (2006). A beginner's guide to evidence-based practice in health and social care. Open University, Maidenhead.

Brown, S. (2013). Evidence- based nursing. $3^{\text {rd }}$ ed., Jones \& Bartlett Learning.

Bursalı, Y; Bağc, Z \& Kök, S. (2014). The relationship between emotional labor and task/contextual/innovative 
job performance: A study with private banking employees in Denizli. European Journal of Research on Education, 2 (2): 221-228

Davies, J. (2012). Nursing and Health: Evidence-based Practice: a survival guide. Pearson, Harlow.

Díaz-Vilela, L; Rodríguez, N; Isla-Díaz, R; Díaz-Cabrera, D; Hernández-Fernaud, E \& Rosales-Sánchez, C. (2015). Relationships between Contextual and Task Performance and Interrater Agreement: Are There Any?. PLoS One, 10 (10).

Greenslade, J \& Jimmieson, N. (2007). Distinguishing between task and contextual performance for nurses: development of a job performance scale. Journal of Advanced Nursing, 58(6): 602-611.

Hair, J. F; Black, W. C; Babin, B. J; Anderson, R. E \& Tatham, R. L. (2006). Multivariate Data Analysis. $6^{\text {th }}$ edition., New York: Macmillion Publishing Company.

Jankingthong, K., and Rurkkhum, S. (2012). Factors affecting job performance: A review of literature. Silpakorn University. Journal of Social Sciences, Humanities, and Arts, 12: 115-127.

Kaburia, C. (2013). Leadership style of school principals and performance of primary schools in Nairobi County of Kenya. Unpublished research project, University of Nairobi, Kenya.

Kovner, A; Elton, J. \& Billings, J. (2005). Evidence-Based Management. Frontiers of Health Services Management, 16: 3-24.

Lemieux-Charles, L \& Champagne, F. (2004). Using Knowledge and Evidence in Healthcare: Multidisciplinary Perspectives.Toronto: University of Toronto Press.

Organ, D; Podsakoff, P \& MacKenzie, S. (2006). Organizational Citizenship Behavior: Its Nature, Antecedents, and Consequences. Thousand Oaks: Sage Publications, Inc.

Parahoo, K. (2006). Nursing Research: principles process and issues. $2^{\text {nd }}$ ed., Palgrave Macmillan, Basingstoke.

Rice, K; Jeongha Hwang, J; Abrefa-Gyan, T \& Powell, K. (2010). Evidence-Based Practice Questionnaire: A Confirmatory Factor Analysis in a Social Work Sample. Advances in Social Work, 11 (2):158 - 173.

Rostami, H; Bahramzadeh, H \& Saeidi, P. (2015). The Relationship between Employees' Empowerment with Job Performance at the Red Crescent Society of North Khorasan. International Journal of Basic Sciences \& Applied Research, 4 (6): 320-322.

Shi, Q; Bert, M; Mary, L; Brian, R \& Joy, C. (2014). A modified evidence-based practice- knowledge, attitudes, behaviour and decisions/outcomes questionnaire is valid across multiple professions involved in pain management. BMC Medical Education, 14 (263): 2 - 9.

Tod, A; Palfreyman, S \& Burke, L. (2004). Evidence-based practice is a time of opportunity for nursing. British Journal of Nursing, 13 (4): $211-216$.

Upton, D \& Upton, P. (2006). Development of an evidence-based practice questionnaire for nurses. Methodological issues in nursing research, 53 (4): 454-458.

Vanden Berghe, J. (2011). Job satisfaction and job performance at the workplace. Unpublished Master's dissertation, Arcada University of Applied Science, Helsinki.

Zadeh, F. (2015). Evidence-Based Management: Theory, Model, Test, and Template. Unpublished PHD Thesis, McMaster University, Ontario, Canada. 